\title{
POOR GLYCEMIC CONTROL IMPACTS LINEAR AND NON- LINEAR DYNAMICS OF HEART RATE IN DM TYPE 2
}

\author{
POBRE CONTROLE GLICÊMICO IMPACTA A DINÂMICA LINEAR E NÃO LINEAR \\ DA FREQUENNCIA CARDÍACA NO DM2
}

Original Article

ARTIGO ORIGINAL

Artículo Original

\author{
CONTROL GLUCÉMICO DEFICIENTE IMPACTA LA DINÁMICA LINEAL Y NO LINEAL \\ DE LA FRECUENCIA CARDÍACA EN EL DM2
}

\author{
Daniela Bassi' (Physiotherapist) \\ Vivian Maria Arakelian² \\ (Physiotherapist) \\ Renata Gonçalves Mendes' \\ (Physiotherapist) \\ Flávia Cristina Rossi Caruso ${ }^{1}$ \\ (Physiotherapist) \\ José Carlos Bonjorno Júnior² \\ (Physician) \\ Katiany Thays Lopes Zangrando' \\ (Physiotherapist) \\ Cláudio Ricardo de Oliveira ${ }^{3}$ \\ (Physician) \\ Jacob Haus ${ }^{4,5}$ (Exercise Science) \\ Ross Arena ${ }^{5,6}$ (Physiotherapist) \\ Audrey Borghi-Silva' \\ (Physiotherapist)
}

1. Universidade Federal de São Carlos (UFSCar), Laboratório Cardiopulmonar, São Carlos, Brasil. 2. Universidade de São Paulo, Departamento de Interunidades de Bioengenharia, São Paulo, Brasil. 3. Universidade Federal de São Carlos (UFSCar), Departamento de Medicina, São Carlos, Brasil.

4. University of Illinois Chicago, Department of Kinesiology and Nutrition 6, College of Applied Health Sciences, Chicago, USA. 5. University of Illinois Chicago, College of Applied Health Sciences, Integrative Physiology Laboratory, Chicago, USA.

6. University of Illinois Chicago, Department of Physical Therapy and Integrative Physiology Laboratory, College of Applied Health Sciences, Chicago, USA.

\section{Correspondence:}

Audrey Borghi Silva Rod. Washington Luis Km 235. Laboratório de Fisioterapia Cardiopulmonar, Departamento de Fisioterapia, Universidade Federal de São Carlos, São Carlos, SP, Brasil. audrey@ufscar.br

\begin{abstract}
Introduction: It is well known that type 2 diabetes mellitus (T2DM) produces cardiovascular autonomic neuropathy (CAN), which may affect the cardiac autonomic modulation. However, it is unclear whether the lack of glycemic control in T2DM without CAN could impact negatively on cardiac autonomic modulation. Objective: To evaluate the relationship between glycemic control and cardiac autonomic modulation in individuals with T2DM without CAN. Descriptive, prospective and cross sectional study. Methods: Forty-nine patients with T2DM (51 \pm 7 years) were divided into two groups according to glycosylated hemoglobin ( $\mathrm{HbA1c}$ ): $\mathrm{G} 1 \leq 7 \%$ and $\mathrm{G} 2>7.0 \%$. Resting heart rate (HR) and RR interval (RRi) were obtained and calculated by linear (Mean iRR; Mean HR; rMSSD; STD RR; LF; HF; LF/HF, TINN and RR Tri,) and non-linear (SD1; SD2; DFa1; DFa2, Shannon entropy; ApEn; SampEn and $C D$ ) methods of heart rate variability (HRV). Insulin, $\mathrm{HOMA-IR}$, fasting glucose and $\mathrm{HbA1} \mathrm{c}$ were obtained by blood tests. Results: G2 (HbA1c $\leq 7 \%$ ) showed lower values for the mean of iRR; STD RR; RR Tri, TINN, SD2, CD and higher mean HR when compared with G1 (HbA1c > 7\%). Additionally, HbA1c correlated negatively with mean $\operatorname{RRi}(r=0.28, p=0.044) ; \operatorname{STD} R R(r=0.33, p=0.017) ; \operatorname{RR} \operatorname{Tri}(r=-0.35, p=0.013), \operatorname{SD} 2(r=-0.39, p=0.004)$ and positively with mean $H R(r=0.28, p=0.045)$. Finally, fasting glucose correlated negatively with STD RR $(r=-0.36, p=0.010) ; R R$ Tri $(r=-0.36, p=0.010) ; \operatorname{TINN}(r=-0.33, p=0.019)$ and SD2 $(r=-0.42, p=0.002)$. Conclusion: We concluded that poor glycemic control is related to cardiac autonomic modulation indices in individuals with T2DM even if they do not present cardiovascular autonomic neuropathy.
\end{abstract}

Keywords: diabetes mellitus, type 2; blood glucose; heart rate; autonomic nervous system; hemoglobin A, glycosylated.

\section{RESUMO}

Introdução: É de conhecimento geral que o diabetes mellitus tipo 2 (DM2) produz neuropatia autonômica cardiovascular (NAC), que pode afetar a modulação autonômica cardíaca. Entretanto, não é claro se a falta de controle glicêmico em diabéticos tipo 2 sem NAC, poderia impactar negativamente na modulação autonômica cardíaca. Objetivo: Avaliar a relação entre controle glicêmico e modulação autonômica cardíaca em indivíduos com DM2 sem neuropatia autonômica cardiovascular. Estudo descritivo, prospectivo e transversal. Métodos: Quarenta e nove pacientes com DM2 (51 \pm 7 anos) foram divididos em dois grupos de acordo com a hemoglobina glicosilada (HbA1c): G1: $\leq 7 \%$ e G2: >7,0\%. A frequência cardíaca de repouso (FC) e intervalo RR (iRR) foram obtidos e calculados por métodos lineares (média iRR; média FC; rMSSD; STD RR; LF; HF; LF/HF, TINN e RR Tri) e não lineares (SD1; SD2; DFa1; DFa2, Entropia de Shannon; ApEn; SampEn e CD) de variabilidade de frequência cardíaca. Insulina, HOMA-IR, glicemia de jejum e HbA1c foram obtidas por análises sanguíneas. Resultados: G2 (HbAlc $\leq 7 \%)$ mostrou valores menores para média de iRR; STD RR; RR Tri, TINN, SD2, CD e maiores para média de FR quando comparado com Gl (HbAlc > 7\%). Adicionalmente, HbAlc correlacionou-se negativamente com media iRR $(r=0,28, p=0,044)$; STD RR ( $r=0,33, p=0,017)$; RR Tri $(r=-0,35, p=0,013)$, SD2 $(r=-0,39, p=0,004)$ e positivamente com média $F C(r=0,28, p=0,045)$. Finalmente, a glicemia de jejum correlacionou-se negativamente com $\operatorname{STD} R R(r=-0,36, p=0,010) ; R R \operatorname{Tri}(r=-0,36, p=0,010) ; \operatorname{TINN}(r=-0,33, p=0,019)$ e SD2 $(r=-0,42, p=0,002)$. Conclusão: Conclui que o controle glicêmico deficiente relaciona-se com índices de modulação autonômica cardíaca em indivíduos com DM2, ainda que não apresentem neuropatia autonômica cardiovascular.

Palavras-chave: diabetes mellitus tipo 2, glicemia, frequência cardíaca, sistema nervoso autônomo, hemoglobina A glicosilada.

\section{RESUMEN}

Introducción: Es de conocimiento general que la diabetes mellitus tipo 2 (DM2) produce neuropatía autonómica cardiovascular (NAC), que puede afectar la modulación autonómica cardíaca. Entretanto, no es claro si la falta de control glucémico en diabéticos tipo 2 sin NAC, podría impactar negativamente en la modulación autonómica cardiaca. Objetivo: Evaluar la relación entre control glucémico y modulación autonómica cardíaca en individuos con DM2 sin neuropatía autonómica cardiovascular. Estudio descriptivo, prospectivo y transversal. Métodos: Cuarenta y 
nueve pacientes con DM2 (51 17 años) fueron divididos en dos grupos de acuerdo con la hemoglobina glucosilada (HbA1c): G1: $\leq 7 \%$ y G2: >7,0\%. La frecuencia cardíaca de reposo (FC) e intervalo RR (iRR) fueron obtenidos y calculados por métodos lineales (promedio iRR; promedio FC; rMSSD; STD RR; LF; HF; LF/HF, TINN y RR Tri) y no lineales (SD1; SD2; DFa1; DFa2, Entropía de Shannon; ApEn; SampEn y CD) de variabilidad de frecuencia cardiaca. Fueron obtenidas insulina, HOMA-IR, glucemia en ayunas y HbA1c a través de análisis sanguíneos. Resultados: G2 (HbA1C $\leq 7 \%$ ) mostró valores menores para el promedio de iRR; STD RR; RR Tri, TINN, SD2, CD y mayores para el promedio de FR al ser comparado con Gl (HbAlc > 7\%). Adicionalmente, HbA1c se correlacionó negativamente con el promedio $\operatorname{iRR}(r=0,28, p=0,044) ; \operatorname{STD} R R(r=0,33, p=0,017)$; $R R \operatorname{Tri}(r=-0,35, p=0,013), \operatorname{SD2}(r=-0,39, p=0,004)$ y positivamente con el promedio $F C(r=0,28, p=0,045)$. Finalmente, la glucemia en ayunas se correlacionó negativamente con STD $R R$ $(r=-0,36, p=0,010) ;$ RR Tri $(r=-0,36, p=0,010) ; \operatorname{TINN}(r=-0,33, p=0,019)$ e SD2 $(r=-0,42, p=0,002)$. Conclusión: Concluimos que el control glucémico deficiente se relaciona con indices de modulación autonómica cardíaca en individuos con DM2, aunque no presenten neuropatía autonómica cardiovascular.

Palabras clave: diabetes mellitus tipo 2, glucemia, frecuencia cardíaca, sistema nervioso autónomo, hemoglobina A glucosilada.

\section{INTRODUCTION}

Diabetes mellitus (DM) is one of the most common metabolic disorders in the world, in which more than $90 \%$ of the cases are type 2 DM (T2DM) ${ }^{1}$. Moreover, it is well known that T2DM is an important and independent risk factor for cardiovascular mortality and morbidity ${ }^{2}$. Most patients with DM develop autonomic neuropathy, which is one of the more common complications in this population ${ }^{3}$. Damage to autonomic nerve fibers that innervate the heart and blood vessels consequently lead to abnormalities in heart rate (HR) control and vascular dynamics ${ }^{4,5}$. Comparatively, the mortality of DM patients manifesting an autonomic neuropathy is markedly higher ${ }^{6,7}$ than DM patients without autonomic neuropathy. Thus, early diagnosis of cardiac autonomic dysregulation is of great clinical in patients with $\mathrm{DM}^{8}$.

In 2007, Vinik and Dan Ziegler showed that heart rate variability (HRV) can accurately detect the presence of a cardiac autonomic neuropathy ${ }^{9}$. In fact, reduced HRV has been recognized as an early hallmark of cardiac autonomic neuropathy and it predicts mortality in patients with ischemic heart disease and $\mathrm{DM}^{10,11}$. Heart rate variability was first analyzed using linear models, such as spectral analysis ${ }^{12}$, however, nonlinear modeling has been recently proposed as a superior method to describe the complexities of HR dynamics ${ }^{13-19}$.

Although poor glycemic is thought to be the most important etiologic factor leading to complications of DM, its effect on linear and nonlinear dynamics of HR in asymptomatic patients is unknown, which was the impetus for the current investigation.

We hypothesized that poor glycemic control would negatively impact both linear and nonlinear dynamics of $\mathrm{HR}$ and that nonlinear indices, in particular, can be an early indicator of autonomic nervous system dysregulation.

\section{MATERIAL AND METHODS}

Descriptive, prospective and cross sectional study. A total of 49 male and female (34 male and 15 female), participants diagnosed with type 2 DM (T2DM), aged $51.8 \pm 6$ years, were divided into two groups according to glycosylated hemoglobin (HbA1c): 1) $\mathrm{G} 1: \leq 7.0 \%$ $(n=10)$ and 2$) G 2:>7.0 \%$, $(n=39)^{20}$, with or without additional coronary heart disease risk factors including hypertension $(\geq 130 \mathrm{mmHg}$ systolic or $\geq 80 \mathrm{mmHg}$ diastolic) and dyslipidemia. Duration of diabetes was based on a self-reported date of diagnosis. Exclusion criteria consisted of a history consistent with heart disease, uncontrolled hypertension, musculoskeletal disorders, and other concomitant respiratory diseases.
The study followed the Declaration of Helsinki guidelines and was approved by the Human Research Ethics Committee of our Institution (protocol number 1318/1). The procedure was explained to each subject separately and all signed written informed consent.

All subjects were investigated in a quiet room from 7:30 to 12:00am. All subjects were instructed to avoid caffeinated and alcoholic beverages 12 hours before the test and not to perform activities requiring moderate-to-heavy physical exertion.

\section{HR and RR interval (RRi) recording}

The HR and RRi were recorded continuously using a Polar S810i telemetry system (Polar Electro Oy, Kempele, Finland) and these data were used to quantify HRV. Each subject rested for 10 min before the initiation of data collection to ensure HR stabilization. Heart rate was then continuously recorded during a $10 \mathrm{~min}$ period of supine rest period.

\section{HRV analysis}

The HR data was transferred to a microcomputer and the RRi series were reviewed by visual inspection. Only segments with $>90 \%$ of pure sinus beats were included in the final analysis. The data were transferred into Kubios HRV analysis software (MATLAB, version 2 beta, Kuopio, Finland) and analyzed with one series of 256 sequential RRi.

The nonlinear dynamic properties of HRV were analyzed using measures such as approximate entropy (ApEn) ${ }^{21}$, correlation dimension (CD $)^{22}$ and Poincaré plot ${ }^{23}$. ApEn quantifies the regularity of time series data and is represented as a simple index for the overall complexity and predictability of each time series. Large values of ApEn indicate high irregularity and smaller values of ApEn indicate a more regular signal. Thus, higher ApEn value reflects better health and function ${ }^{21}$. The nonlinear analysis of the Poincare plot of RRi was applied and the following two descriptors of the Poincare plot were used in the study: (i) SD1 - the standard deviation measuring the dispersion of points in the plot perpendicular to the line-of-identity. This parameter is usually interpreted as a measure of short-term HRV, which is caused mainly by respiratory sinus arrhythmia (parasympathetic modulation); and (ii) SD2 - the standard deviation measuring the dispersion of points along the identity line, which is interpreted as a measure of both short and long-term HRV (overall HRV) ${ }^{23}$.

Linear traditional measures in the time domain HRV analysis were evaluated by calculating the following, widely accepted, parameters: (i) mean of RR and its standard deviation (STD RR), also called SDNN, in $\mathrm{ms}$; (ii) square root of the mean squared differences of successive RRi (rMSSD) in ms; and (iii) geometrical forms as the integral of the 
RRi histogram divided by the height of the histogram (RR tri index) and the baseline width of the RRi histogram (TINN) in ms (8). STD $\mathrm{RR}$ represents a global index of HRV (overall HRV) and reflects all the cyclic components responsible for variability in the recording period; (ii) rMSSD reflect alterations in autonomic modulation that are predominantly vagally mediated; and (iii) the geometrical HRV indices are an estimative of the overall HRV ${ }^{24}$. This multivariate approach allows for a comprehensive assessment of cardiac autonomic function.

\section{Laboratory analysis}

Blood specimens were obtained after an overnight fast for all measurements. HbA1c was measured in a central laboratory by anion-exchange high-performance liquid chromatography (Variant II, Bio Rad, Berkeley, California), coupled with a fluorescence detector method certified by the National Glycohemoglobin Standardization Program ${ }^{20}$.

Insulin resistance was evaluated by the Homeostatic model (HOMA- IR) which is calculated by the following formula: (fasting plasma glucose $(\mathrm{mg} / \mathrm{dl}) \times$ fasting plasma insulin $(\mu \mathrm{U} / \mathrm{ml}) / 22.5]^{25}$. Fasting plasma glucose was measured by an enzymatic method using an $\mathrm{AU} 680^{\circledR}$ (Beckman Couter, Suarlée (NAMUR) Belgium) and fasting plasma insulin was measured by a chemiluminescent assay (UniCel ${ }^{\circledR}$ Dxl 800, Pasadena, California). Total cholesterol (total-C), low-density lipoprotein cholesterol (LDL-C), high-density lipoprotein cholesterol (HDL-C) and triglycerides were measured by an enzymatic method AU $680^{\circledR}$ (Beckman Couter, Suarlée (NAMUR) Belgium) ${ }^{26}$.

\section{Statistical analysis}

Data are reported as mean \pm SD, unless otherwise specified. All data were verified for the assumptions of normality and comparisons between groups (G1 vs G2) were performed using unpaired T-Tests. Correlation of key variables was assessed using Spearman's correlation coefficients. Tests with a p-value $<0.05$ were considered statistically significance. Statistical analyses were carried using Statistica 5.5 (StatSoft Inc., Tulsa, USA).

\section{RESULTS}

A total of 49 patients were evaluated over a 1-year period. Table 1 describes the clinical characteristics of all subjects and compares them according to an $\mathrm{HbA} 1 \mathrm{C}$ threshold (G1 and G2). There were no significant

Table 1. Patient characteristics, stratified by assessment of glycosylated hemoglobin (HbA1c).

\begin{tabular}{|c|c|c|c|}
\hline & $\begin{array}{c}\mathrm{HbA1c} \leq 7 \% \\
(\mathrm{n}=10)\end{array}$ & $\begin{array}{c}\text { HbA1c }>7 \% \\
(n=39)\end{array}$ & $P$ value \\
\hline Sex & 6 male/4 female & 28 male/11 female & - \\
\hline Age (years) & $51.2 \pm 7.7$ & $51.2 \pm 7.2$ & 0.86 \\
\hline Weight (Kg) & $82 \pm 17.6$ & $82.9 \pm 17.2$ & 0.59 \\
\hline Height $(\mathrm{cm})$ & $170 \pm 0.1$ & $170 \pm 0.1$ & 0.41 \\
\hline BMI $\left(\mathrm{kg} / \mathrm{m}^{2}\right)$ & $29.7 \pm 5.2$ & $29.6 \pm 5.3$ & 0.95 \\
\hline $\mathrm{HbA1C}(\%)$ & $6.4 \pm 0.4$ & $9.2 \pm 1.5$ & $<0.0001$ \\
\hline $\mathrm{FPG}(\mathrm{mg} / \mathrm{dL})$ & $125.1 \pm 50.3$ & $168.9 \pm 59.7$ & 0.01 \\
\hline Duration DM (years) & $1.9 \pm 1.0$ & $6.5 \pm 4.1$ & $<0.001$ \\
\hline \multicolumn{4}{|l|}{ Risk factors CVD } \\
\hline $\mathrm{SAH}$ & $5(50 \%)$ & $20(51.3 \%)$ & 1.00 \\
\hline $\mathrm{Ow} / \mathrm{Ob}$ & $8(80 \%)$ & $31(79.5 \%)$ & 1.00 \\
\hline Dyslipidemia & $8(80 \%)$ & $28(71.79 \%)$ & 1.00 \\
\hline \multicolumn{4}{|l|}{ Oral hypoglycemics } \\
\hline Biguanide & $6(60 \%)$ & $19(48.7 \%)$ & 0.66 \\
\hline Sulfonyurea & $4(40 \%)$ & $20(51.3 \%)$ & 0.57 \\
\hline DPP4 inhibitor & $1(10 \%)$ & -- & 0.40 \\
\hline Combination & $3(30 \%)$ & $10(25.6 \%)$ & 0.19 \\
\hline
\end{tabular}

differences in baseline characteristics: age, height, weight and BMI. Fasting plasma glucose was significantly higher in $\mathrm{G} 2$ and duration of diabetes was significant higher in G1 when compared to G2. Additionally, there were no significant differences regarding risk factors for cardiovascular disease and oral hypoglycemic medications.

The results of HRV indices are presented in table 2. Linear indices (Mean RRi, STR RR, RR Tri and TINN) were significantly lower in G2 when compared to G1, with the exception of mean HR, which was significantly higher in the G2 when compared to G1.Non-linear dynamics of HR indices (SD2 and CD) demonstrated significantly lower values in $\mathrm{G} 2$ when compared to $\mathrm{G} 1$.

Table 3 lists Spearman correlation coefficient (r) results, demonstrating a negative and significant association between HRV linear indices and both $\mathrm{HbA} 1 \mathrm{c}$ and FPG values. In addition, a negative relationship between SD2 and CD were observed with HbA1c and FPG. Duration of DM was not correlated with any HRV indices.

Table 2. Linear and non-linear heart rate variability indices for both groups.

\begin{tabular}{|c|c|c|c|}
\hline & $\begin{array}{c}\text { G1 } \\
\mathrm{HbA} 1 \mathrm{c}<7 \%(\mathrm{n}=10)\end{array}$ & $\begin{array}{c}\text { G2 } \\
\mathrm{HbA} 1 \mathrm{c}>7 \%(\mathrm{n}=39)\end{array}$ & $P$ value \\
\hline \multicolumn{4}{|l|}{ Linear Indices } \\
\hline Mean RRi (ms) & $928.47 \pm 67.83$ & $844.25 \pm 117.64$ & 0.01 \\
\hline Mean HR (bpm) & $65.12 \pm 4.91$ & $72.45 \pm 9.55$ & 0.01 \\
\hline rMSSD (ms) & $26.33 \pm 15.24$ & $18.26 \pm 13.92$ & 0.09 \\
\hline STD RR (ms) & $34.92 \pm 19.51$ & $21.13 \pm 12.85$ & 0.02 \\
\hline $\mathrm{LF}(\mathrm{nu})$ & $70.77 \pm 26.89$ & $65 \pm 20.36$ & 0.22 \\
\hline $\mathrm{HF}(\mathrm{nu})$ & $29.23 \pm 26.89$ & $35 \pm 20.36$ & 0.22 \\
\hline $\mathrm{LF} / \mathrm{HF}$ & $6.28 \pm 6.3$ & $3.28 \pm 3.64$ & 0.22 \\
\hline TINN & $149 \pm 50.32$ & $107.82 \pm 65.72$ & 0.04 \\
\hline RR Tri & $9.02 \pm 5.12$ & $5.57 \pm 3.07$ & 0.01 \\
\hline \multicolumn{4}{|l|}{ Nonlinear Indices } \\
\hline SD1 (ms) & $18.94 \pm 10.65$ & $13.08 \pm 9.89$ & 0.07 \\
\hline SD2 (ms) & $61.94 \pm 25.06$ & $37.7 \pm 19.11$ & 0.006 \\
\hline DF a1 & $1.31 \pm 0.41$ & $1.26 \pm 0.29$ & 0.66 \\
\hline DF a2 & $0.95 \pm 0.12$ & $0.92 \pm 0.19$ & 0.57 \\
\hline SE & $3.2 \pm 0.28$ & $3.21 \pm 0.33$ & 0.80 \\
\hline ApEn & $0.97 \pm 0.13$ & $1.03 \pm 0.12$ & 0.07 \\
\hline SampEn & $1.35 \pm 0.37$ & $1.41 \pm 0.32$ & 0.88 \\
\hline$C D$ & $2.46 \pm 1.14$ & $1.08 \pm 1.38$ & 0.004 \\
\hline
\end{tabular}

Data are expressed as Mean \pm SD. HRV: heart rate variability; Mean RRi: mean of R-R intervals; Mean HR: mean heart rate; rMSSD: square root of the mean squared differences of successive RR; STD RR: standard deviation of RR; LF un: band low frequency; HF un: band high frequency; LF/HF: ratio bands; TINN: baseline width of the RR histogram; RR tri: integral of the RR histogram divided by the height of the histogram; SD: standard deviation of instantaneous R-R interval variability, DF: short-term correlation properties of RRi; SE: Shannon Entropy; ApEn: approximate entropy; SampEn: sample entropy, CD: correlation dimension.

Table 3. Spearman correlation coefficient ( $r$ ) between indices of heart rate variability and laboratory tests.

\begin{tabular}{c|c|c}
\hline Heart rate variability index & Laboratory test & \\
\hline & HbA1c & P value \\
\hline Mean RRi (ms) & $r=-0.28$ & 0.044 \\
\hline Mean HR & $r=0.28$ & 0.045 \\
\hline STD RR & $r=-0.33$ & 0.017 \\
\hline RR Tri & $r=-0.35$ & 0.013 \\
\hline SD2 (ms) & $r=-0.39$ & 0.004 \\
\hline TINN & Fasting glucose & 0.019 \\
\hline STD RR & $r=-0.33$ & 0.010 \\
\hline RR Tri & $r=-0.36$ & 0.010 \\
\hline SD2 & $r=-0.36$ & 0.002
\end{tabular}

Indices of heart rate variability: Mean RRi: mean of R-R intervals; Mean HR: mean heart rate; STD RR: standard deviation of RR; RR Tri: integral of the RR histogram divided by the height of the histogram; SD: standard deviation of instantaneous R-R interval variability. 


\section{DISCUSSION}

The main findings of the present study are: (i) individuals with T2DM with poor glycemic control presented with a greater impairment in linear and nonlinear HR dynamics compared to those with better glycemic control; and (ii) poor glycemic control negatively affects HRV dynamics, confirming our hypothesis. To our knowledge, this is the first study to address these relationships. The findings of the present study stress the clinical importance of early and ongoing strategies to manage blood glucose levels in T2DM in order to deter the numerous physiologic consequences of this condition, including a negative effect on HRV.

\section{Negative effects of poor glycemic control on cardiac auto- nomic control}

A reduction in HRV is common in patients with DM and it is also associated with adverse poor cardiovascular prognosis s7,28 $^{27}$ and stroke ${ }^{29}$. The current study demonstrated that poor metabolic control negatively affects cardiac autonomic modulation in these patients, as observed by reduced HRV values. Therefore, in subjects with T2DM who are already prone to cardiac autonomic dysfunction, lack of glycemic control further compounds poor autonomic control of HR. Reduced HR variability is the earliest indicator of cardiovascular autonomic neuropathy and is thus important to prevent ${ }^{9}$.

An interesting finding of the present study was the majority of subjects analyzed presented with poor glycemic control (79.6\%). We expected the converse to be observed since all subjects were in treatment, receiving frequent medical follow-up. However, in the context of poor glycemic control, our study is consistent with Viana et al. ${ }^{30}$, in 2013, which described the clinical profile of Brazilian patients with T2DM managed by the public healthcare system.

\section{Linear analysis on HRV and glycemic control}

Specifically, in the present study, we observed that the time domain of HRV indicated that patients that who presented with a $\mathrm{HbA1c}>7$ had a lower Mean RRi, STD RR, RR Tri and TINN. In 2005, Faulkner et al. 2005 compared autonomic control of HR in adolescents with T2DM, which had been diagnosed for at least a year, to those with T1DM; finding significantly lower levels of HRV time domain indices in the former group ${ }^{31}$.

CAN in DM is the result of complex interactions between the degree of glycemic and disease duration. It has been shown that chronic hyperglycemia promotes progressive autonomic neural dysfunction in a manner that parallels the development of peripheral neuropathy contro $^{32}$. Corroborating with our study, Poanta et al. ${ }^{33}$ demonstrated a lack of autonomic control evaluated by HRV in subjects with T2DM without signs of cardiovascular disease.

In the current study, we did assess insulin levels and therefore were unable to perform correlations with HRV indices. Charles et al. recently found that insulin levels were inversely and significantly associated with both HF and LF HRV, although only among those with higher levels of obesity and lower levels of physical activity ${ }^{34}$. Future studies is needed to assess this relationship.

Recently, Pal et al. ${ }^{35}$. showed positive correlation between HOMA-IR and linear indices of HRV, such as the LF/HF ratio, in the cohort with a family history of T2DM. However, in the current study, we did not identify an association between HRV indices and HOMA-IR. These differences may be related in differences in characteristics between cohorts.

\section{Nonlinear analysis oh HRV and glycemic control}

Nonlinear analysis of HRV indicated that subjects that presented with a $\mathrm{HbA} 1 \mathrm{c}>7 \%$ presented with lower nonlinear indices of HRV (i.e., SD2), indicating that total HRV as well as parasympathetic modulation is reduced in this subgroup. In addition, the CD index, which is an important nonlinear index that represents the adaptability of the autonomic system, was also reduced in the presence of higher HbA1c. A lower $C D$ reflects poor degrees of freedom of the cardiac pacemaker and, therefore, a reduced range of possible adaptative responses to stimuli in an ever-changing environment ${ }^{22}$

Improving metabolic control is a challenging clinical task in patients with T2DM. The results of the present study showed that the majority of our subjects did not have adequate glycemic control $(\mathrm{HbA} 1 \mathrm{c}>$ 7=79.6\%), even in recently diagnosed cases. Conversely, Khattab et al. ${ }^{36}$, studying factors associated with poor glycemic control, showed that the proportion of patients with poor glycemic control was high and associated with a longer duration since diagnosis and poor compliance with diabetes self-care management.

Hyperglycemia is considered a permissive pathogenesis factor ${ }^{37}$ because it activates various biochemical pathway leading to the development and progression of CAN ${ }^{32}$. The injury mechanisms of sympathetic and parasympathetic branches in DM are not completely understood. The pathogenesis of CAN is complex and involves a cascade of pathways activated by hyperglycemia resulting in neuronal ischemia and cellular death 38,39

In accordance with our results, Lind et al. ${ }^{40}$, observed that the poor glycemic control, defined as a $\mathrm{HbA} 1 \mathrm{c}>7 \%$ was an independent risk factor for hospitalizations due to heart dysfunction in patients with T2DM. Considering that poor HRV and reduced HR complexity are associated with poor cardiovascular prognosis and higher risk of arrhythmias ${ }^{41}$ and sudden death ${ }^{42}$, poor glycemic control can result in a loss of autonomic nervous adjustments. In this way, Matsushita et. al. ${ }^{43}$, using a cut-off for $\mathrm{HbA} 1 \mathrm{c}$ of $5.5-6.0 \%$, showed a higher incidence of heart failure in a middle-aged population without DM, suggesting that chronic hyperglycemia may contribute to the development of heart failure.

HRV is commonly analyzed using linear models such as spectral analysis. Nonlinear analysis differs from traditional approaches because it considers qualitative properties of $\mathrm{HR}$ time series and could provide early and additional information ${ }^{13,17-19}$ of HR dynamics. Therefore, in this study, subjects with a HbA1c > 7\% showed reduced cardiovascular complexity, which is considered to an early marker of risk for cardiovascular disease $\mathrm{e}^{13}$.

A recent study evaluated HRV in individuals with T2DM, without CAN, in response to an active postural maneuver and they showed that this cohort presented with higher cardiac sympathetic modulation ${ }^{44}$ However, the complexity of HRV was not influenced by the imbalance of autonomic modulation in individuals with $\mathrm{T}_{2} \mathrm{DM}^{45}$. In parallel, the current study was the first to show higher $\mathrm{HbA1c}$; in other words, uncontrolled and persistent hyperglycemia affects non-linear dynamics of $\mathrm{HR}$, which has been considered an important early marker of abnormal cardiac modulation damage. The current study corroborates with Nayak et al. ${ }^{45}$ who observed that subjects with DM undergoing regular treatment with insulin and oral hypoglycemic agents did not demonstrate a correlation between CAN score and duration of diabetes. However, Nolan et al. ${ }^{46}$, found that duration of DM was independently and inversely associated with HRV markers of vagal HR modulation (HF power and rMSSD) and total R-R variability (SDNN) among male subjects. Taken together, these data suggest that the glycemic control may be time-dependent with duration of DM.

\section{CONCLUSION}

In conclusion, the findings of the current study suggest that patients with T2DM with poor glycemic control, as demonstrated by higher HbA1c values above the recommended target, are more susceptible to poor autonomic nervous control of HR. In this way, new 
strategies are necessary to improve glycemic control in this population, since poor management causes a host of detrimental physiologic abnormalities, including altered CAN, which can be one of the first steps toward manifestation of cardiovascular disease.

\section{ACKNOWLEDGEMENTS}

The authors gratefully acknowledge staff of the Laboratório de Fisioterapia Cardiopulmonar.
This study was supported by a Research Grant from CNPq (478789/2011-2) - Conselho Nacional de Desenvolvimento Científico e Tecnológico - CNPq, Brazil, and Fundação de Amparo à Pesquisa do Estado de São Paulo, SP, Brasil - FAPESP 2009/01842-0.

All authors have declared there is not any potential conflict of interests concerning this article.

\section{REFERENCES}

1. Korc M. Diabetes mellitus in the era of proteomics. Mol Cell Proteomics. 2003;2(6):399-404.

2. Wei M, Gaskill SP, Haffner SM, Stern MP. Effects of diabetes and level of glycemia on all-cause and cardiovascular mortality. The San Antonio Heart Study. Diabetes Care. 1998;21(7):1167-72.

3. Spallone V, Menzinger G. Diagnosis of cardiovascular autonomic neuropathy in diabetes. Diabetes. 1997;46 Suppl 2:567-76.

4. Osterhues $\mathrm{HH}$, Grossmann $\mathrm{G}$, Kochs $\mathrm{M}$, Hombach V. Heart-rate variability for discrimination of different types of neuropathy in patients with insulin-dependent diabetes mellitus. J Endocrinol Invest. 1998;21(1):24-30

5. Schumer MPJS, Pfeifer MA. Cardiovascular autonomic neuropathy testing in patients with diabetes. Diabet Spectr. 1998;11:223-7.

6. Ewing DJ, Borsey DQ, Bellavere F, Clarke BF. Cardiac autonomic neuropathy in diabetes: comparison of measures of R-R interval variation. Diabetologia. 1981;21(1):18-24.

7. Moțățăianu A, Bălaşa R, Voidăzan S, Bajkó Z. Cardiovascular autonomic neuropathy in context of other complications of type 2 diabetes mellitus. Biomed Res Int. 2013;2013:507216.

8. Heart rate variability: standards of measurement, physiological interpretation and clinical use. Task Force of the European Society of Cardiology and the North American Society of Pacing and Electrophysiology. Circulation. 1996;93(5):1043-65.

9. Vinik Al, Ziegler D. Diabetic cardiovascular autonomic neuropathy. Circulation. 2007;115(3):387-97.

10. Maser RE, Mitchell BD, Vinik Al, Freeman R. The association between cardiovascular autonomic neuropathy and mortality in individuals with diabetes: a meta-analysis. Diabetes Care. 2003;26(6):1895-901

11. Valensi P, Extramiana F, Lange C, Cailleau M, Haggui A, Maison Blanche $P$, et al. Influence of blood glucose on heart rate and cardiac autonomic function. The DESIR study. Diabet Med. 2011;28(4):440-9.

12. Melkonian D, Korner A, Meares R, Bahramali H. Increasing sensitivity in the measurement of heart rate variability: the method of non-stationary RR time-frequency analysis. Comput Methods Programs Biomed. 2012;108(1):53-67.

13. Huikuri HV, Mäkikallio TH, Perkiömäki J. Measurement of heart rate variability by methods based on nonlinear dynamics. J Electrocardiol. 2003;36(Suppl):95-9.

14. Wagner CD, Persson PB. Chaos in the cardiovascular system: an update. Cardiovasc Res. 1998;40(2):257-64.

15. Signorini MG. Nonlinear analysis of heart rate variability signal: physiological knowledge and diagnostic indications. Conf Proc IEEE Eng Med Biol Soc. 2004;7:5407-10.

16. Saeed M. Fractals analysis of cardiac arrhythmias. Scientific World Journal. 2005;5:691-701.

17. Huikuri HV, Mäkikallio T, Airaksinen KE, Mitrani R, Castellanos A, Myerburg RJ. Measurement of heart rate variability: a clinical tool or a research toy? J Am Coll Cardiol. 1999;34(7):1878-83.

18. Jokinen V, Tapanainen JM, Seppänen T, Huikuri HV. Temporal changes and prognostic significance of measures of heart rate dynamics after acute myocardial infarction in the beta-blocking era. Am J Cardiol. 2003;92(8):907-12.

19. Mäkikallio TH, Huikuri HV, Hintze U, Videbaek J, Mitrani RD, Castellanos A, et al. Fractal analysis and time- and frequency-domain measures of heart rate variability as predictors of mortality in patients with heart failure. Am J Cardiol. 2001;87(2):178-82

20. American Diabetes Association. Standards of medical care in diabetes--2013. Diabetes Care. 2013;36(Suppl 1):11-66.

21. Pincus SM. Approximate entropy as a measure of system complexity. Proc Natl Acad Sci USA. 1991;88(6):2297-301.

22. Schubert C, Lambertz M, Nelesen RA, Bardwell W, Choi JB, Dimsdale JE. Effects of stress on heart rate complexity--a comparison between short-term and chronic stress. Biol Psychol. 2009;80(3):325-32.

23. Piskorski J, Guzik P. Geometry of the Poincaré plot of RR intervals and its asymmetry in healthy adults. Physiol Meas. 2007:28(3):287-300.

24. Sztajzel J. Heart rate variability: a noninvasive electrocardiographic method to measure the autonomic nervous system. Swiss Med Wkly. 2004;134(35-36):514-22

25. Diretrizes da Sociedade Brasileira de Diabetes. São Paulo: Sociedade Brasileira de Diabetes; 2009
26. Matthews DR, Hosker JP, Rudenski AS, Naylor BA, Treacher DF, Turner RC. Homeostasis model assess ment: insulin resistance and beta-cell function from fasting plasma glucose and insulin concentration in man. Diabetologia. 1985;28(7):412-9.

27. Forsblom CM, Sane T, Groop PH, Tötterman KJ, Kallio M, Saloranta C, et al. Risk factors for mortality in Type II (non-insulin-dependent) diabetes: evidence of a role for neuropathy and a protective effect of HLA-DR4. Diabetologia. 1998;41(11):1253-62.

28. La Rovere MT, Bigger JT Jr, Marcus FI, Mortara A, Schwartz PJ. Baroreflex sensitivity and heart-rate variability in prediction of total cardiac mortality after myocardial infarction. ATRAMI (Autonomic Tone and Reflexes After Myocardial Infarction) Investigators. Lancet. 1998;351(9101):478-84.

29. Töyry JP, Niskanen LK, Länsimies EA, Partanen KP, Uusitupa MI. Autonomic neuropathy predicts the development of stroke in patients with non-insulin-dependent diabetes mellitus. Stroke. 1996;27(8):1316-8.

30. Viana LV, Leitão CB, Kramer CK, Zucatti AT, Jezini DL, Felício J, et al. Poor glycaemic control in Brazilian patients with type 2 diabetes attending the public healthcare system: a cross-sectional study. BM Open. 2013;3(9):e003336.

31. Faulkner MS, Quinn L, Rimmer JH, Rich BH. Cardiovascular endurance and heart rate variability in adolescents with type 1 or type 2 diabetes. Biol Res Nurs. 2005;7(1):16-29.

32. Pop-Busui R. Cardiac autonomic neuropathy in diabetes: a clinical perspective. Diabetes Care 2010;33(2):434-41.

33. Poanta L, Porojan M, Dumitrascu DL. Heart rate variability and diastolic dysfunction in patients with type 2 diabetes mellitus. Acta Diabetol. 2011;48(3):191-6.

34. Charles LE, Andrew ME, Sarkisian K, Shengqiao L, Mnatsakanova A, Violanti JM, et al. Associations between insulin and heart rate variability in police officers. Am J Hum Biol. 2014;26(1):56-63.

35. Pal GK, Adithan C, Ananthanarayanan PH, Pal P, Nanda N, Durgadevi T. Sympathovagal imbalance contributes to prehypertension status and cardiovascular risks attributed by insulinresistance, inflammation, dyslipidemia and oxidative stress in first degree relatives of type 2 diabetics. PLoS One. 2013:8(11):e78072

36. Khattab M, Khader YS, Al-Khawaldeh A, Ajlouni K. Factors associated with poor glycemic control among patients with type 2 diabetes. J Diabetes Complications. 2010;24(2):84-9.

37. Ziegler D. Diabetic cardiovascular autonomic neuropathy: prognosis, diagnosis and treatment. Diabetes Metab Rev. 1994:10(4):339-83

38. Dimitropoulos G, Tahrani AA, Stevens MJ. Cardiac autonomic neuropathy in patients with diabetes mellitus. World J Diabetes. 2014;5(1):17-39.

39. Edwards JL, Vincent AM, Cheng HT, Feldman EL. Diabetic neuropathy: mechanisms to management Pharmacol Ther. 2008;120(1):1-34.

40. Lind M, Olsson M, Rosengren A, Svensson AM, Bounias I, Gudbjörnsdottir S. The relationship between glycaemic control and heart failure in 83,021 patients with type 2 diabetes. Diabetologia. 2012;55(11):2946-53.

41. Veglio M, Borra M, Stevens LK, Fuller JH, Perin PC. The relation between QTc interval prolongation and diabetic complications. The EURODIAB IDDM Complication Study Group. Diabetologia. 1999;42(1):68-75.

42. Kahn JK, Sisson JC, Vinik Al. Prediction of sudden cardiac death in diabetic autonomic neuropathy J Nucl Med. 1988:29(9):1605-6.

43. Matsushita K, Blecker S, Pazin-Filho A, Bertoni A, Chang PP, Coresh J, et al. The association of hemoglobin a1 $\mathrm{c}$ with incident heart failure among people without diabetes: the atherosclerosis risk in communities study. Diabetes. 2010;59(8):2020-6

44. Moura-Tonello SC, Takahashi AC, Francisco CO, Lopes SL, Del Vale AM, Borghi-Silva A, et al. Influence of type 2 diabetes on symbolic analysis and complexity of heart rate variability in men. Diabetol Metab Syndr. 2014;6(1):13.

45. Nayak UB, Acharya V, Jain H, Lenka S. Clinical assessment of the autonomic nervous system in diabetes mellitus and its correlation with glycemic control. Indian J Med Sci. 2013;67(1-2):13-22.

46. Nolan RP, Barry-Bianchi SM, Mechetiuc AE, Chen MH. Sex-based differences in the association between duration of type 2 diabetes and heart rate variability. Diab Vasc Dis Res. 2009;6(4):276-82. 